\title{
Determinants of Municipal Government Employees' OCBE
}

\author{
Umi Lestari ${ }^{1}$, Lenny C Nawangsari ${ }^{2}$ \\ \{umilestari983@gmail.com¹, lenny.christina@mercubuana.ac.id² \\ Universitas Mercu Buana, Jakarta ${ }^{12}$
}

\begin{abstract}
Sustainability is a global concern today, based on the growing awareness of the impact on the environment caused by human activities. Every individual in the organization has an important role in realizing the green performance of an organization. The main objectives of this paper were to analyze the Effect of Green Transformational Leadership, Organizational Commitment, and Autonomous Motivation on Organizational Citizenship Behavior for the Environment (OCBE) in employees of Tangerang F ood Security Agency. This study was a quantitative study involving 56 employees as respondents. The data were collected using questionnaires and then analyzed with SEM (Structural Equation Modelling). The results of this study showed that all variables had a positive and significant effect on OCBE employees of Tangerang Food Security Agency. The limitation of this study was that the data have not been completed with in-depth interviews with respondents. Managerial implications that can be applied to encourage OCBE are varied but can begin with the application of transformational leadership values. The originality of this paper is to discuss how green transformational leadership, organizational commitment and autonomous motivation influence OCBE in municipal government employees.
\end{abstract}

Keywords: Green Transformational Leadership, Organizational Commitment, Autonomous Motivation, OCBE

\section{Introduction}

The role of local governments in sustainable development for the environment has been recognized throughout the world. One indicator is the holding of the first UN World Congress of Local Governments for a Sustainable Future in 1990 and the formation of ICLEI (Local Governments for Sustainability) in 1991[1]. Local governments have a strategic role in making policies related to the environment such as providing environmentally friendly public transportation, stimulating the green economy, controlling air pollution, and other green policies [2]. One of the regions that support the national capital, Tangerang is inseparable from various environmental issues. Problems that arise include pollution, garbage, land-use change, reduced green open space, and others. Tangerang Municipal Government pays attention by making sustainable development one of its priorities. One of the missions of the Tangerang Municipal Government as stated in the Medium-Term Development Plan for 20192023 is "Jointly Enhancing the Development of Sustainable and Environmentally Friendly City Facilities and Infrastructures."

The role of all members of the organization in realizing sustainable development is very important even at the individual level. Employees are important stakeholders in an 
organization. The environmentally friendly behavior of an organization is very dependent on the role of its employees [3]. Employees who are willing to take environmentally friendly actions outside their formal responsibilities are known as Organizational Citizenship Behavior for the Environment (OCBE). OCBE describes voluntary behavior that specifically benefits the environment. Examples of OCBE are turning off the room lights after they are used. These energy-saving behaviors are beneficial to the environment and indirectly benefit the organization [4]. The importance of OCBE is clearly discussed in environmental literature [5].

This study aims to identify the Effect of Green Transformational Leadership, Organizational Commitment, and Autonomous Motivation on Organizational Citizenship Behavior for the Environment (OCBE) on employees of the Tangerang Food Security Department. This study is important for as a whole; this behavior can increase OCBE employees who lead to the success of the Tangerang mission related to sustainability and environmentally sound development. Based on previous studies, it is known that several factors might affect OCBE. Green transformational leadership effectively promotes OCBE, but the four dimensions of Transformational leadership have different paths and strengths in influencing OCBE [6]. One of the antecedent variables that affect OCBE is organizational commitment [7]. Autonomous motivation has a stronger influence on increasing persistence behavior, welfare, psychological health, and pro environmental behaviors [8].

\subsection{Literature Review and Hypothesis Development 1.2.1 Organizational Citizenship Behavior for the Environment (OCBE)}

OCBE is a wise action by employees in an organization that leads to environmental improvement without any appreciation or request from the organization. Four factors are considered prominent in influencing OCBE, namely Environmental Concern, Organizational Commitment, Perceived Corporate Social Performance, and Supervisory Support [7]. The three OCBE measurement scales are Eco-Initiatives, Eco-Civic Management, and EcoHelping. Eco-Initiatives are individual initiatives in organizations to behave and provide wise advice in efforts to improve the environmental performance of the organization. Eco-Civic Management is the voluntary participation of individuals to play a role in pro-environment programs and activities organized by the organization. Meanwhile, Eco-Helping is an act of helping colleagues to integrate environmental problems in the organization [9].

\subsubsection{Green transformational leadership and OCBE}

The leadership model is very important in realizing the green performance of an organization. Green transformational leadership is the behavior of leaders who can motivate followers to achieve the environmental goals of the organization and inspire followers to take pro-environmental actions [10]. Transformational leadership has four dimensions, namely idealized influence, inspirational motivation, intellectual stimulation, and individualized consideration [11]. Managers who exhibit environmental transformational leadership behavior are expected to be able to communicate clear and coherent environmental visions in their areas of responsibility [12]. If leaders apply the values of green transformational leadership, subordinates might be more receptive and internalize the green values of their leaders and eventually increase spontaneous green behavior [13]. Based on the description above, the hypothesis can be formulated as follows:

H1: Green Transformational Leadership has a positive and significant effect on the OCBE of Employees of Tangerang Food Security Agency. 


\subsubsection{Organizational commitment and OCBE}

One of the main predictors of OCBE is an organizational commitment [7]. Organizational commitment is the desire to maintain membership of an organization, recognize organizational goals, organizational success, the loyalty of an employee, and willingness to make maximum efforts on behalf of the organization [14]. Organizational commitment includes three dimensions, namely Affective Commitment (emotional attachment to the organization), Normative Commitment (perceived attachment to organizational goals), Continuance Commitment (commitment to remain a member of the organization) [15]. Employees who have a strong commitment to the organization will be willing to carry out activities that are in line with the goals and values of the organization, including corporate goals related to sustainability [16]. Based on the description above, the hypothesis can be formulated as follows:

H2: Organizational Commitment has a positive and significant effect on the OCBE of Employees of Tangerang Food Security Agency.

\subsubsection{Autonomous motivation and OCBE}

SDT theory identifies several types of motivation and groups the types into two categories, autonomous motivation, and controlled motivation. Autonomous motivation is when people are willing to engage in an activity because they find the activity interesting and carry out the activity on their own volition [17]. Dimensions of autonomous motivation are identified as motivation and intrinsic motivation. Identified motivation encourages someone to be more oriented towards long-term goals and to try to persevere in doing activities that may not be interesting, but are important according to them [18]. Intrinsic motivation encourages a person to focus on activities and to produce emotions such as interests and excitement [18]. Compared with controlled motivation, autonomic motivation has a stronger influence on increased behavior persistence, well-being, psychological health, and pro-environmental behaviors. Thus, the hypothesis can be formulated as follows:

H3: Autonomous motivation has a positive and significant effect on the OCBE of employees of the Tangerang Food Security Agency.

From previous studies, three variables, Green Transformational Leadership, Organizational Commitment, and Autonomous Motivation each affect OCBE. Therefore, it is necessary to further study whether these variables jointly influence OCBE. Hence, the hypothesis can be formulated as follows:

H4: Green Transformational Leadership, Organizational Commitment, and Autonomous Motivation have a significant effect on the OCBE of employees of Tangerang Food Security Agency.

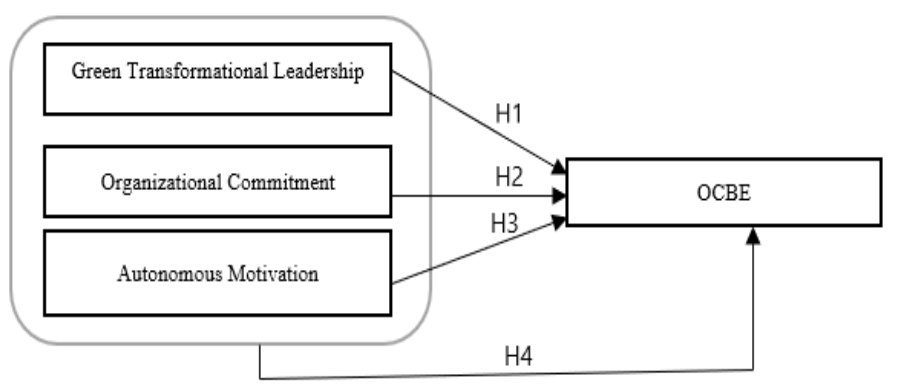

Fig 1. Hypothesis Model 


\section{Research Method}

\subsection{Respondents}

The respondents consisted of 56 employees of the Tangerang Food Security Agency. AS many as $53.57 \%$ of respondents were women. The age range of respondents was $20-60$ years old and around $35.71 \%$ were aged between $30-40$ years old. $62.5 \%$ of respondents had a bachelor's degree. The work experience of the respondents ranged from 1-30 years where around $50 \%$ of them had a work period of more than 10 years.

\subsection{Measurement and Analyses}

Data collection was carried out through questionnaires. This study involved three independent variables and one dependent variable. All four variables were measured on a Likert scale of $5(1=$ strongly disagree, $2=$ disagree, $3=$ neutral, $4=$ agree, $5=$ strongly agree). There were 10 statement items in Green Transformational Leadership. A representative item was that my leader "talks about the importance of protecting the environment (idealized influenced)," "speaks enthusiastically about what we need to do to protect the environment (inspirational motivation)," "encourages employees to see the environmental problem in new ways (intellectual stimulation," and "provides guidance and training on environmental issues (consideration individualized)" [12]. There were 9 (nine) items for Organizational Commitment such as "feeling happy to spend an organization's career (affective commitment)," "belief in the value of being true to the organization (normative commitment)," "and the loss if you leave the organization (continuous commitment)" [19].

There were six items for autonomous motivation such as "engaging in pro-environment behavior at work because it is possible to achieve goals that are considered important (identified motivation)" and "engaging in pro-environment behavior at work because they enjoy doing it (intrinsic motivation)" [12]. There were 10 (ten) items for OCBE such as "doing pro-environment actions that contribute to the image of the organization (eco-civic engagement)," voluntary taking actions and initiatives that are environmentally friendly in their daily work activities (eco-initiative)," and "spontaneously taking time to help coworkers who carry out pro-environment activities (eco-helping)" [9]. Researchers use a quantitative approach to test objective theories by examining the relationship between variables. The data analysis technique used in this study was Structural Equation Modeling (SEM) on Partial Least Square (PLS).

\section{Results and Discussion}

\subsection{Outer Model Evaluation}

This model defines how each indicator relates to its latent variable. Tests conducted on the outer model using the Confirmatory Factor Analysis (CFA) technique. There were two tests conducted at this stage, namely the validity test and the reliability test. The results of the validity test indicate that the indicators meet convergent validity if the loading factor value is above 0.7 . The next validity test was discriminant validity test based on the value of Average Variance Extracted (AVE) and Cross Loading. The value of AVE is considered to be good if it has a value greater than 0.50 [20]. Reliability tests were determined from the Composite Reliability (CR) and Cronbach's alpha (CA) values for each indicator block. The construct is declared to be reliable if it has a composite reliability value above 0.70 and a Cronbach's alpha 
value above 0.6 [20]. The results of the validity and reliability test are presented in Table 1 below.

Table 1. Results of the reliability and validity tests

\begin{tabular}{|c|c|c|c|c|c|c|c|c|c|c|c|}
\hline Variable & Item: & Loading: & AVE & $C_{\mathbf{R}}$ & $C_{A}$ & Variable & Item: & Loading: & AVE & $C_{\mathbf{R}}$ & $\mathrm{CA}$ \\
\hline Green & GIL1 & 0.890 & 0.631 & 0.945 & 0.935 & Autonomous & AMI & 0.906 & 0.703 & 0.934 & 0.915 \\
\hline Transformational & GIL2 2 & 0.883 & & & & Motivation & $\mathrm{AM} 2$ & 0.887 & & & \\
\hline \multirow[t]{8}{*}{ Leadership } & GTL3 & 0.904 & & & & & AM3 & 0.815 & & & \\
\hline & GTL4 & 0.837 & & & & & AM4 & 0.859 & & & \\
\hline & GTLS & 0.874 & & & & & AMS & 0.913 & & & \\
\hline & GTLG & 0.835 & & & & & AMG & 0.844 & & & \\
\hline & GIL7 & 0.848 & & & & & & & & & \\
\hline & GTLS & 0.878 & & & & & & & & & \\
\hline & GIL9 & 0.889 & & & & & & & & & \\
\hline & CITL 10 & 0.888 & & & & & & & & & \\
\hline Variable & Item: & Leading: & AVE & CR & $C_{A}$ & Variable & Item: & Leading: & AVE & $C R$ & $C A$ \\
\hline Organizational & $O C 1$ & 0.909 & 0.715 & 0.957 & 0.950 & OCBE & OCBE1 & 0.879 & 0.746 & 0.967 & 0.962 \\
\hline \multirow{9}{*}{ Commitment } & $O C 2$ & 0.915 & & & & & ОСве2 2 & 0.867 & & & \\
\hline & $O C 3$ & 0.848 & & & & & OCBE 3 & 0.880 & & & \\
\hline & $O C 4$ & 0.920 & & & & & OCВEA & 0.881 & & & \\
\hline & OCs & 0.859 & & & & & OCBES & 0.905 & & & \\
\hline & $O C 6$ & 0.889 & & & & & OCBE & 0.901 & & & \\
\hline & $0 \subset 7$ & 0.900 & & & & & OCBE7 & 0.890 & & & \\
\hline & OCs & 0.871 & & & & & OCBES & 0.878 & & & \\
\hline & OC9 & 0.906 & & & & & OCBE9 & 0.898 & & & \\
\hline & & & & & & & OCBE 10 & 0006 & & & \\
\hline
\end{tabular}

\subsection{Inner Model Evaluation}

Inner model evaluation was conducted by looking at R-square, as explained in table 2 below:

Table 2. R-Square Values of the Research Model

\begin{tabular}{ccc}
\hline Construct & $\boldsymbol{R}$ Square & $\boldsymbol{R}$ Square Adjusted \\
\hline OCBE & 0.83 & 0.82
\end{tabular}

The obtained R-square value was 0.830 which means that $83.0 \%$ of employees' OCBC variables were influenced by the Green Transformational Leadership, Organizational Commitment, and Autonomous Motivation variables while the remaining $17.0 \%$ was influenced by other variables outside the study. Hypothesis testing was done by P-value. The results of hypothesis testing using SmartPLS 3.2.8 can be seen in figure 2 and table 3 as follows:

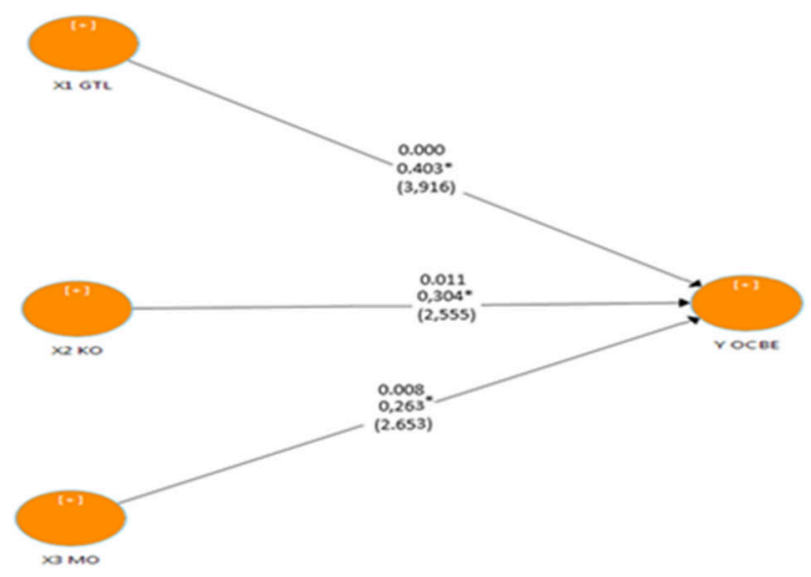

Fig 2. Testing the Inner Model 
Table 3. The Values of Path coefficient, t-Statistics, and P-Value

\begin{tabular}{|c|c|c|c|c|c|c|c|}
\hline Hypothesis & Relationship & $\begin{array}{c}\text { Original } \\
\text { Sample }(0)\end{array}$ & $\begin{array}{l}\text { Sample Mean } \\
\text { (M) }\end{array}$ & $\begin{array}{l}\text { Standard } \\
\text { Deviation } \\
\text { (STDEV) }\end{array}$ & $\begin{array}{l}\text { T Statistics } \\
(\mid \mathbf{O} / \text { STDEV } \mid)\end{array}$ & $\begin{array}{c}P \\
\text { Values }\end{array}$ & Result \\
\hline \multicolumn{8}{|l|}{ Direct Effect } \\
\hline H1 & $\begin{array}{l}\text { - Green Transformational } \\
\text { Leadership -> OCBE }\end{array}$ & 0.403 & 0.411 & 0.103 & 3.916 & 0.000 & Supported \\
\hline $\mathrm{H} 2$ & $\begin{array}{l}\text { - Organizational Commitment - } \\
>\mathrm{OCBE}\end{array}$ & 0.304 & 0.294 & 0.119 & 2.555 & 0.011 & Supported \\
\hline $\mathrm{H} 3$ & $\begin{array}{l}\text { - Autonomous Motivation -> } \\
\text { OCBE }\end{array}$ & 0.263 & 0.263 & 0.099 & 2.653 & 0.008 & Supported \\
\hline
\end{tabular}

Consistent with Hypothesis 1, Green Transformational Leadership had a positive and significant effect on OCBE (P-values $<0.05$ ). Employees who see their superiors applying green transformational leadership values will make them more involved in pro-environment behavior. As suggested by Hypothesis 2, organizational commitment had a positive and significant effect on OCBE (P-values $<0.05$ ). The higher the employees' commitment to the organization, the more involved in pro-environment behavior in the organization. The direct effect between autonomous motivation and OCBE was positive and significant ( $\mathrm{P}$ values $<$ 0.05). This finding is consistent with Hypothesis 3. Meanwhile, for Hypothesis 4, the simultaneous influence of Green Transformational Leadership variables and Organizational Commitment on Autonomous Motivation and OCBE of Employees were calculated by the $\mathrm{f}$ test/f-statistic. If $\mathrm{f}$-test $>\mathrm{f}$-statistic, then Green Transformational Leadership, Organizational Commitment, and Autonomous Motivation influence on OCBE Employees (Y) of Tangerang Food Security Agency.

Table 4. Value of $\mathrm{f}$-test and $\mathrm{f}$-statistic

\begin{tabular}{cccc}
\hline Construct & $f$-test & $f$-statistic & Description \\
\hline OCBE & 129.17 & 2.78 & Simultaneous Influence
\end{tabular}

Following Hypothesis 4, Green Transformational Leadership, Organizational Commitment, and Autonomous Motivation simultaneously influenced OCBE.

\subsection{Discussion}

\subsubsection{The Effect of Green Transformational Leadership on OCBE}

Green Transformational Leadership has a positive and significant effect on the OCBE of employees of the Tangerang Food Security Agency. This finding is in line with a previous study that states that transformational leadership styles can effectively improve employees' OCBE [6]. To support the values of transformational leadership, there should be an emphasis on these values during the decision on the appointment of leaders as well as during training and leadership development. One of the materials provided should emphasize the values of Green Transformational Leadership. The managerial implications of this study are as a reference for organizational leaders that psychological barriers that prevent employees from sharing knowledge and experience about pro-environmental problems or behavior might be reduced through transformational leadership styles.

\subsubsection{Effect of Organizational Commitment on OCBE}

Organizational commitment has a positive and significant effect on the OCBE of employees of the Tangerang Food Security Agency. Previous studies also stated that 
organizational commitment has a positive correlation with OCBE [9]. Employees who have more commitment to the company tend to be involved with several organizational initiatives, including efforts to improve environmental performance [21]. The managerial implication of this study is to prove that the higher the organizational commitment of employees, the initiative to do more to the environment will also increase. This can be used as a benchmark for Tangerang Food Security Agency leaders to strive to increase OCBE employees through increasing organizational commitment with various actions and activities. One of the HRM practices that might be used to increase organizational commitment is education and training [22]. Training related to the environment will result in changes in employee attitudes and behavior [23].

\subsubsection{Effect of Autonomous Motivation on OCBE}

Autonomous motivation has a positive and significant effect on the OCBE of employees of the Tangerang Food Security Agency. Previous studies also stated that autonomous motivation has a positive relationship with OCBE [24]. Under self-determination theory (SDT), organizations that have concern for the welfare of employees by providing autonomy, competence, and linkages enable the employees to develop their ability to help others and also tend to have positive behavior [8]. The competencies provided are not only focused on the main tasks but also material about the environment. One of them is by increasing the number of people who have competencies related to the environment by holding workshops and the use of multimedia behavioral modeling [25]. The managerial implication of the study on the influence of autonomous motivation on OCBE of employees of Tangerang Food Security Agency is that employees might be involved in pro-environment activities for they consider it important. This could be an opportunity for organizations to continue to promote activities that minimize the impact on the environment.

\subsubsection{Effect of Green Transformational Leadership, Organizational Commitment, Autonomous Motivation on OCBE}

Green transformational leadership, organizational commitment, autonomous motivation simultaneously Influence the OCBE of Tangerang Food Security Agency employees. Considering the importance of leadership in realizing organizational goals, the Tangerang Food Security Agency leaders are obliged to have the ability to influence the behavior of his subordinates to find ideas and be able to act wisely in contributing to achieving organizational goals. The main managerial implication of the influence of green transformational leadership, organizational commitment, and simultaneous autonomous motivation on OCBE are that leaders have to instill transformational leadership values into themselves. Leaders are required to provide flexibility to employees to develop ideas about solving environmental problems. Furthermore, open communication will make employees feel valued. Theoretical analysis shows that transformational leadership and organizational commitment are strongly and positively related, either directly or indirectly through mediators [26]. The more dominant transformational leadership style applied by the leader might increasingly increase employee commitment to the organization [27]. Employees' perceptions of transformational leadership are also positively related to individual autonomous motivation [28]. 


\section{Conclusions}

According to SEM analysis results, it might be concluded that the positive relationship between green transformational leadership, organizational commitment, and autonomous motivation towards OCBE can be confirmed. Taken together the three variables also have a significant effect on OCBE. To improve employees' OCBE, organizational leaders have to encourage creativity, innovation, and critical thinking in problem-solving and encourage the use of new ways of solving environmental problems. Increasing employee commitment to the organization also requires to be improved by involving employees in training and development activities. Positive interactions with leaders tend to make employees interested in taking roles in realizing organizational goals, including behaving pro-environment. The limitation of this study was that the data generated were only based on a questionnaire instrument based on the perception of respondents' answers. The data have not yet completed with in-depth interviews with respondents or related parties at the Tangerang Municipal Government, especially the Tangerang Food Security Agency. Future studies are expected to use several methods in obtaining data and information such as observation and direct interviews in addition to using a questionnaire to obtain in-depth information.

\section{References}

[1] D. Salskov-Iversen, "Environmental Sustainability Strategy and City Government," Dev. Strateg. Public Manag., pp. 211-226, 2014.

[2] L. Y. Syah, S. N. Nafsiah, and K. Saddhono, "Linear regression statistic from accounting information system application for Employee integrity," J. Phys. Conf. Ser., vol. 1, 2019.

[3] Z. Han, Q. Wang, and X. Yan, "How responsible leadership predicts organizational citizenship behavior for the environment in China," Leadersh. Organ. Dev. J., vol. 40, no. 3, pp. 305-318, 2019.

[4] D. J. Piacun, "F Ostering O Rganisational C Itizenship B Ehaviour for the B Ehaviour in a S Chool -B Ased S Etting," 2017.

[5] S. Cheema, B. Afsar, and F. Javed, "Employees' corporate social responsibility perceptions and organizational citizenship behaviors for the environment: The mediating roles of organizational identification and environmental orientation fit," Corp. Soc. Responsib. Environ. Manag., vol. 27, no. 1, pp. 9-21, 2020.

[6] L. Mi, X. Gan, T. Xu, R. Long, L. Qiao, and H. Zhu, “A new perspective to promote organizational citizenship behaviour for the environment: The role of transformational leadership," J. Clean. Prod., vol. 239, p. 118002, 2019.

[7] B. F. Daily, J. W. Bishop, and N. Govindarajulu, "A conceptual model for organizational citizenship behavior directed toward the environment," Bus. Soc., vol. 48, no. 2, pp. 243-256, 2009.

[8] E. L. Deci and R. M. Ryan, "Self-determination theory: A macrotheory of human motivation, development, and health," Can. Psychol., vol. 49, no. 3, pp. 182-185, 2008.

[9] O. Boiral and P. Paillé, "Organizational Citizenship Behaviour for the Environment: Measurement and Validation," J. Bus. Ethics, vol. 109, no. 4, pp. 431-445, 2012.

[10] Y. S. Chen and C. H. Chang, "The Determinants of Green Product Development Performance: Green Dynamic Capabilities, Green Transformational Leadership, and Green Creativity," $J$. Bus. Ethics, vol. 116, no. 1, pp. 107-119, 2013.

[11] B. M. Bass, "From transactional to transformational leadership: Learning to share the vision," Organ. Dyn., vol. 18, no. 3, pp. 19-31, 1990.

[12] L. M. Graves, J. Sarkis, and Q. Zhu, "How transformational leadership and employee motivation combine to predict employee proenvironmental behaviors in China," J. Environ. Psychol., vol. 35, pp. 81-91, 2013. 
[13] X. Wang, K. Zhou, and W. Liu, "Value congruence: A study of green transformational leadership and employee green behavior," Front. Psychol., vol. 9, no. OCT, pp. 1-8, 2018.

[14] A. Aydin, Y. Sarier, and Ş. Uysal, "The effect of gender on organizational commitment of teachers: A meta analytic analysis," Kuram ve Uygulamada Egit. Bilim., vol. 11, no. 2, pp. 628632, 2011.

[15] J. P. Meyer and N. J. Allen, "Science 2008 Navarro," Hum. Resour. Manag. Rev., vol. 1, no. 1, pp. 61-89, 1991.

[16] E. Lamm, J. Tosti-kharas, and E. G. Williams, Group \& Organization Management. 2013.

[17] M. Gagné and E. L. Deci, "Self-determination theory and work motivation," J. Organ. Behav., vol. 26, no. 4, pp. 331-362, 2005.

[18] K. D. Burton, J. E. Lydon, D. U. D’Alessandro, and R. Koestner, "The differential effects of intrinsic and identified motivation on well-being and performance: Prospective, experimental, and implicit approaches to self-determination theory," J. Pers. Soc. Psychol., vol. 91, no. 4, pp. 750-762, 2006.

[19] N. J. Allen and J. P. Meyer, "The measurement and antecedents of affective, continuance and normative commitment to the organization," pp. 1-18, 1990.

[20] I. Ghozali, Structural Equation Modeling : Metode Alternatif Degan Partial Least Squares (PLS), I. Semarang: Badan Penerbit Universitas Diponegoro, 2014.

[21] E. Temminck, K. Mearns, and L. Fruhen, "Motivating Employees towards Sustainable Behaviour," Bus. Strateg. Environ., vol. 24, no. 6, pp. 402-412, 2015.

[22] W. Bikker, "How to improve organizational commitment among young employees by means of HRM .," 2016.

[23] L. C. Nawangsari and A. H. Sutawidjaya, "How the Green Human Resources Management (GHRM) Process Can Be Adopted for the Organization Business?," vol. 65, no. Icebef 2018, pp. 463-465, 2019.

[24] H. P. R. Priyankara, F. Luo, A. Saeed, S. A. Nubuor, and M. P. F. Jayasuriya, "How does leader's support for environment promote organizational citizenship behaviour for environment? A multi-theory perspective," Sustain., vol. 10, no. 1, 2018.

[25] I. Self-determined, P. Behavior, N. M. Aitken, L. G. Pelletier, and D. E. Baxter, "Nicole Michelle Aitken, Luc G. Pelletier, and Daniel Edgar Baxter School of Psychology, University of Ottawa, Ottawa, Canada.," vol. 8, no. 2, pp. 153-162, 2016.

[26] S. Alshahrani, "ORGANISATIONAL COMMITMENT AND TRANSFORMATIONAL LEADERSHIP IN DIFFERENT CONTEXTS : STRONG AND COMPLEX RELATIONSHIP AS REFLECTED ORGANISATIONAL COMMITMENT AND TRANSFORMATIONAL LEADERSHIP IN DIFFERENT CONTEXTS : STRONG AND COMPLEX,” no. May, 2017.

[27] M. Feizi, E. Ebrahimi, and N. Beheshti, "Investigating the relationship between transformational leadership and organizational commitment of high school teachers in Germi," vol. 3, pp. 17-30, 2014.

[28] J. Chua and O. B. Ayoko, "Employees' self-determined motivation , transformational leadership and work engagement," 2019. 